\title{
DNA-promoted assembly of the active tetramer of the Mu transposase
}

\author{
Tania A. Baker and Kiyoshi Mizuuchi \\ Laboratory of Molecular Biology, NIDDK, National Institutes of Health, Bethesda, Maryland 20892 USA
}

\begin{abstract}
A stable tetramer of the Mu transposase (MuA) bound to the ends of the Mu DNA promotes recombination. Assembly of this active protein-DNA complex from monomers of MuA requires an intricate array of MuA protein-binding sites on supercoiled DNA, divalent metal ions, and the Escherichia coli HU protein. Under altered reaction conditions, many of these factors stimulate assembly of the $\mathrm{MuA}$ tetramer but are not essential, allowing their role in formation of the complex to be analyzed. End-type MuA-binding sites and divalent metal ions are most critical and probably promote a conformational change in $\mathrm{MuA}$ that is necessary for multimerization. Multiple MuA-binding sites on the DNA contribute synergistically to tetramer formation. DNA superhelicity assists cooperativity between the sites on the two Mu DNA ends if they are properly oriented. HU specifically promotes assembly involving the left end of the Mu DNA. In addition to dissecting the assembly pathway, these data demonstrate that the tetrameric conformation is intrinsic to MuA and constitutes the form of the protein active in catalysis.
\end{abstract}

[Key Words: Phage Mu; DNA transposition; HU; MuA tetramer; Enhancer]

Received June 12, 1992; revised version accepted August 10, 1992.

Multiple sequence elements bound by specific proteins are a common feature of many sites of action on DNA such as promoters, enhancers, replication origins, and recombination loci. The importance of protein assembly on these DNA sites is being recognized in many cases, yet the details of how it is achieved are not well understood. Mu transposition is an ideal system to study the mechanisms underlying the construction of proteinDNA complexes. The reactions are relatively simple, the protein-DNA complexes formed are very stable, and multiple DNA sites are specifically required during initial complex assembly (Mizuuchi et al. 1992; Surette and Chaconas 1992).

The DNA cleavage and joining reactions central to $\mathrm{Mu}$ transposition are promoted by the $\mathrm{Mu}$ transposase ( $\mathrm{MuA}$ ) acting simultaneously on the two ends of the phage DNA. These reactions occur in the context of higher order protein-DNA complexes. Three stable proteinDNA complexes on the reaction pathway have been described and characterized: (1) The stable synaptic complex (SSC), in which MuA is bound tightly to the two $\mathrm{Mu}$ ends, pairing them together (Mizuuchi et al. 1992); (2) the cleaved donor complex (CDC), also called the type-I transpososome, in which a single-stranded cleavage has been introduced between the $\mathrm{Mu}$ and the flanking host sequences at each $\mathrm{Mu}$ end (Craigie and Mizuuchi 1987; Surette et al. 1987); and (3) the strand transfer complex (STC), also called the type-II transpososome, in which the donor DNA ends are covalently joined to the target DNA (Surette et al. 1987).

Each of these complexes has a common basic struc- ture: MuA protein is bound tightly to the three end-most MuA-binding sites on the Mu DNA (Fig. 1) (Kuo et al. 1991; Lavoie et al. 1991; Mizuuchi et al. 1991, 1992). The DNA cleavage sites, which lie 6 bp away from the endmost MuA-binding sites, are also covered by the protein. The complexes contain a tetramer of MuA (Lavoie et al. 1991; Mizuuchi et al. 1992/ that mediates pairing by simultaneously binding to the two $\mathrm{Mu}$ DNA ends (Craigie and Mizuuchi 1987; Surette et al. 1987; Mizuuchi et al. 1992). The tetrameric MuA bound to the $\mathrm{Mu}$ ends is the active complex for the donor DNA cleavage and strand transfer reactions. No MuA protein in addition to that assembled into the tetramer in the SSC is needed for the subsequent reaction stages (Mizuuchi et al. 1992; Surette and Chaconas 1992). Thus, assembly of this complex is a critical step in transposition.

Many requirements in the transposition reaction have been shown to be necessary before DNA cleavage, specifically for assembly of this MuA-donor DNA complex (Fig. 1) (Mizuuchi et al. 1992; Surette and Chaconas 1992). (1) The two $\mathrm{Mu}$ ends must be in their proper orientation on a single DNA molecule; (2) the internal activating sequence [(IAS) also called the transpositional enhancer] must be present; (3) the donor DNA must be supercoiled; and (4) the amino-terminal domain of $\mathrm{MuA}$ and (5) the Escherichia coli integration host factor (IHF) protein (Surette et al. 1989), both of which bind to the IAS; $(6)$ the $E$. coli hydroxyurea (HU) protein; and (7) divalent metal ions are also important cofactors for tetramer assembly. Each end of the Mu DNA contains three end-type MuA-binding sites, called L1, L2, and L3 on the 
Figure 1. Cartoon of MuA-binding sites on donor DNA and structure of the SSC. The donor DNA carries six end-type MuA-binding sites-three at each end-shown as large black arrows. The relative orientation of the sites with respect to one another is shown by the direction of the arrowheads. The IAS is made up of multiple sites bound by the very amino-terminal domain of the MuA protein. These sites are also bound by the Mu repressor and are shown as $\mathrm{Ol}$ and O2. The IHF also binds to a sequence within the IAS. The tetrameric configuration of MuA, although an intrinsic stable form of the protein bound to the end sites, does not form efficiently in solution in the absence of the factors shown. Thus, multiple sequence elements on the donor DNA, divalent metal ions, HU, IHF, and DNA superhelicity all function to provide a kinetically accessible pathway for the formation of the MuA tetramer-donor DNA complex. In the final complex, only the $\mathrm{Ll}, \mathrm{R} 1$, and R2 MuA-binding sites are stably bound by the protein. This complex is active for the subsequent reaction steps, and the remaining sites become dispensable.

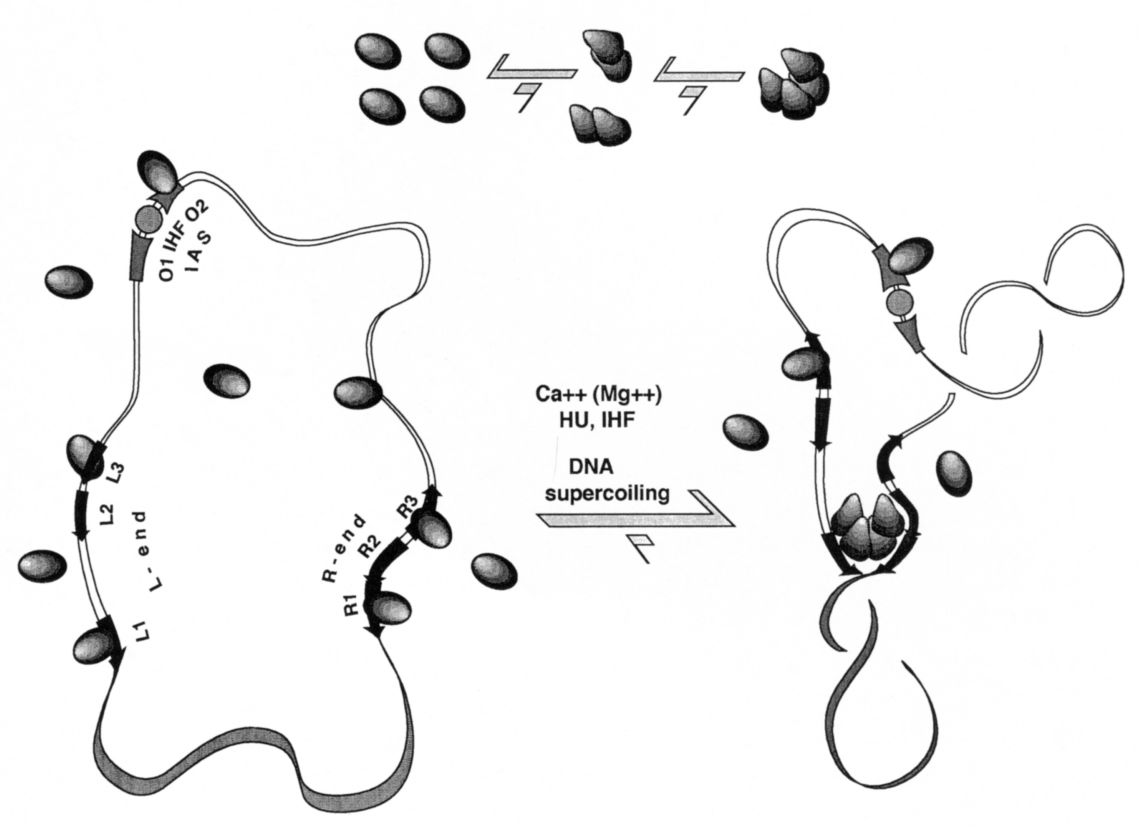

left end (L-end) and R1, R2, and R3 on the right end (R-end) (Craigie et al. 1984). The IAS also contains multiple MuA-binding sites that are recognized by a different region of the MuA protein than are the end-type sites (Nakayama et al. 1987; Leung et al. 1989; Mizuuchi and Mizuuchi 1989).

How does this complicated array of sites and factors result in assembly of the active MuA-donor DNA complex? Under standard conditions, all of the required factors cooperatively promote assembly of the active complex; in the absence of any of them, no intermediate in assembly has been detected. Because a critical aspect of formation of the SSC is the conversion of MuA from the monomeric to the tetrameric form, we have investigated reaction conditions that influence the multimerization of MuA. The use of solvent conditions that favor multimerization of MuA has allowed us to begin dissecting the role of the multiple factors in the assembly process.

\section{Results}

End-type MuA-binding sites are essential for assembly of the active tetramer of $\mathrm{MuA}$

To investigate the role of the specific features of the donor DNA in the assembly of the MuA-DNA complex, mini-Mu plasmids lacking some of the MuA-binding sites were assayed for their ability to support oligomerization of MuA by cross-linking with the homo-bifunctional protein cross-linking agent dithio-bis-|succinimidyl propionate) (DSP) (Fig. 2A). As expected from previous results (Lavoie et al. 1991; Mizuuchi et al. 1992), under normal reaction conditions the complete $\mathrm{Mu}$ donor plasmid supported tetramer formation, whereas most of its derivatives did not. Of the variants tested, only the plasmid lacking the R3 site $(\Delta R 3)$ supported tetramer formation by MuA. This dispensability of R3 is consistent with previous results that R3 is not essential for $\mathrm{Mu}$ transposition in vivo (Groenen et al. 1985) or in vitro (Lavoie et al. 1991). Deletion of the IAS (AIAS), or inversion of one $\mathrm{Mu}$ end relative to the other (such that the two ends were in direct, rather than inverted orientation; wrong ori) prevented tetramer formation; in these cases, MuA remained mostly monomeric, although some dimers were detected.

In contrast, when dimethylsulfoxide (DMSO) (15\%) was included in the reactions, all of the mini-Mu plasmids supported tetramer assembly by MuA (Fig. 2A). The IAS was unnecessary ( $\triangle I A S$ ), as was the proper relative orientation of the Mu DNA ends (wrong ori). Even plasmids carrying only a single $\mathrm{Mu}$ end ( $\mathrm{L}$ - or R-end) supported tetramer assembly. The yield of MuA tetramer in the reactions containing the single $\mathrm{Mu}$ end plasmids could not be attributed to the activity of the low level of plasmid dimers present in the DNA preparation. Furthermore, agarose gel electrophoresis of reaction mixtures (run with and without protein cross-linking) indicated that most complexes contained a single monomeric plasmid (data not shown; see below).

Although DMSO allowed tetramer assembly on plasmids not normally active, $\mathrm{Mu}$ DNA sequences were still essential. Tetramers were not detected in the reaction containing DNA that lacked any $\mathrm{Mu}$-related sequences ( $\phi \mathrm{X} 174 \mathrm{RF}$ ) or in that lacking DNA (no DNA). Divalent metal ions, $\mathrm{Mg}^{2+}, \mathrm{Mn}^{2+}$, or $\mathrm{Ca}^{2+}$, were still essential 

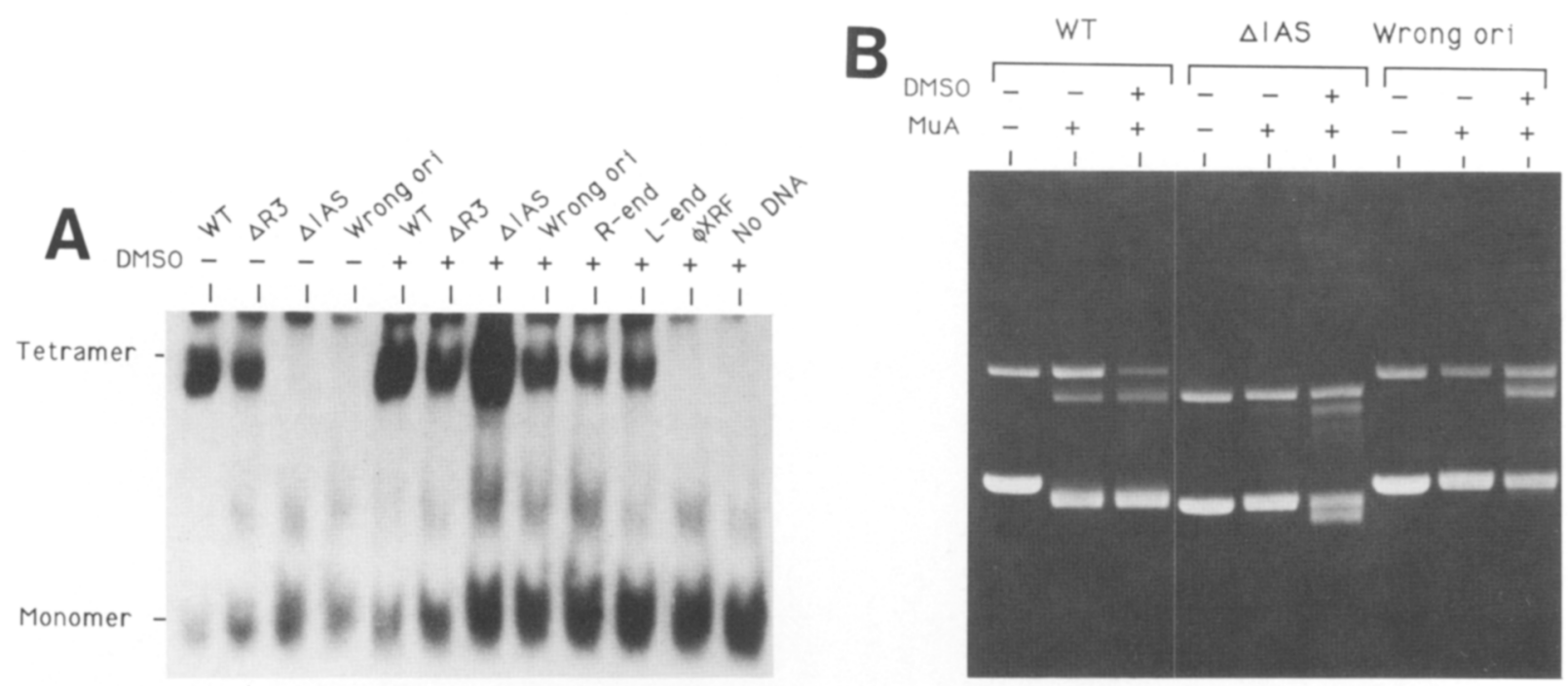

Figure 2. DNA requirement for formation of the active MuA tetramer in the presence and absence of DMSO. Incubations were for $30 \mathrm{~min}$ at $30^{\circ} \mathrm{C}$ before cross-linking. The identities of the plasmid derivatives present in the reactions are shown above the lanes. The L-end plasmid also carried the IAS; the R-end plasmid did not. (A) Western blot of MuA protein after cross-linking with DSP. Reactions contained 15\% DMSO, where indicated. $(B)$ Agarose gel of DNA showing DNA cleavage and strand transfer promoted by MuA. In each set of three lanes, the first is plasmid DNA that has not been incubated with MuA. In reactions containing MuA and the wild-type plasmid, nearly all of the DNA runs as a supercoiled circle slightly faster in mobility than the starting DNA; this is one of the four possible isomers produced during intramolecular strand transfer, as has been described previously (Maxwell et al. 1987; Baker et al. 1991). On the wrong orientation plasmid, none of the isomers generated by intramolecular strand transfer will be supercoiled; the products, therefore, run closer to the nicked circle band.

even in the presence of DMSO (data not shown). In addition, tetramer formation displayed an unusually steep dependence on the reaction temperature; complex formation was five to six times slower at $22^{\circ} \mathrm{C}$ than at $30^{\circ} \mathrm{C}$ (data not shown). This influence of temperature indicates that some step in the assembly process involves a relatively high activation energy.

The MuA tetramers formed during the incubation with DMSO were active in donor DNA cleavage and strand transfer. In the absence of DMSO, only the wildtype plasmid (and the one lacking R3; data not shown) was cleaved and gave rise to strand transfer products (Fig. 2B). The other deletion plasmids appeared unaltered by MuA during the reaction. In the presence of DMSO, however, the $\triangle$ IAS plasmid and that carrying the inverted $\mathrm{Mu}$ ends were efficiently cleaved and recombined by MuA. DMSO therefore relaxes the requirements for both tetramer formation and the chemical steps of transposition, indicating that the MuA complexes made in the presence of DMSO are functional. On the wild-type plasmid, the rate of appearance and distribution of strand transfer products were similar in the presence or absence of DMSO, suggesting that identical complexes formed under these two conditions.

The minimum DNA sequence needed to promote MuA tetramer assembly in the presence of DMSO was analyzed by assaying individual sequence elements from the $\mathrm{Mu}$ L-end. The L-end contains four elements involved in $\mathrm{Mu}$ transposition (Fig. 3A): the CA dinucleotide at the site of donor cleavage and the L1, L2, and L3 copies of the 22-bp MuA end-type-binding site. The L1 sequence differs from L2 and L3 by being directly adjacent to the cleavage site and by being stably bound by the MuA tetramer in the SSC, CDC, and STC (Kuo et al. 1991; Lavoie et al. 1991; Mizuuchi et al. 1991, 1992). The IAS is naturally located $\sim 900 \mathrm{bp}$ from the left cleavage site and was also present on the L-end plasmid.

In the presence of DMSO, the isolated L-end had a similar activity to the mini-Mu containing both ends when assayed after incubation at $30^{\circ} \mathrm{C}$ for $30 \mathrm{~min}$ (Fig. 3B). Deletion of the IAS did not affect the ability of this plasmid to function as an assembly cofactor (L-end -IAS). To further isolate the minimal sequence required for assembly, synthetic oligonucleotides containing individual binding sites were cloned into pUC19, which does not support tetramer formation by $\mathrm{MuA}$ (vector). The Ll sequence, with its associated cleavage site $(\mathrm{L} 1+\mathrm{CA})$ promoted efficient tetramer assembly under these conditions. Removal of the cleavage site did not diminish this activity (L1 - CA). The isolated L3 sequence on a plasmid was also active, whether or not it had an accompanying artificially added cleavage site (L3 and $\mathrm{L} 3+\mathrm{CA})$. In contrast to the activities of these endtype sites, the IAS alone did not support tetramer assembly (data not shown). Thus, in the presence of DMSO, a single copy of a 22-bp MuA-binding site on a plasmid can promote tetramerization of MuA protein.

The plasmids with only a single MuA-binding site also supported DNA cleavage and strand transfer in the presence of DMSO provided that an appropriately positioned 


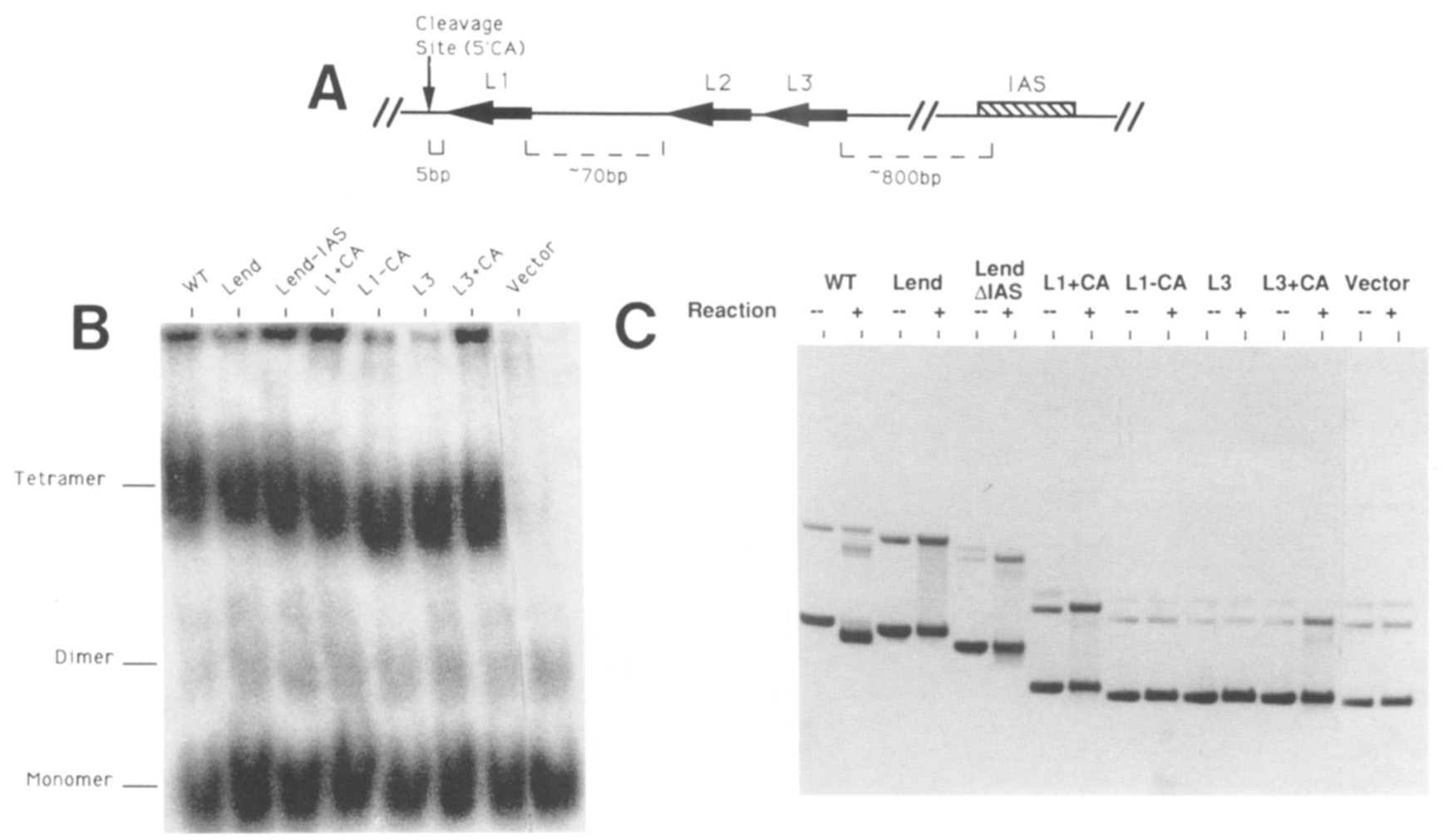

Figure 3. Minimal DNA sequences required for formation of the active MuA tetramer. Reactions were as described in Fig. 2, except all samples included $15 \%$ DMSO. The results after incubation for $30 \mathrm{~min}$ at $30^{\circ} \mathrm{C}$ are shown; the relative activity of the L-end derivatives was similar at $5 \mathrm{~min}$, whereas the wild-type plasmid was substantially more active at early time points (see Fig. 6) $(A)$ Map of the sequence elements on the L-end; $(B)$ Western blot of the cross-linked MuA protein; $(C)$ agarose gel of the reaction products. The contrast of the gel picture was reversed by making an intermediary negative. Plasmids used in the reactions are labeled above the lanes. The vector, pUC19, is the parent plasmid of the derivatives carrying the single MuA-binding sites. The ladder of bands and the smear between the supercoiled and nicked DNA positions are the intramolecular strand transfer products.

cleavage site was also present (Fig. $3 \mathrm{C}$ ). In addition to the nicked circular form resulting from donor cleavage by $\mathrm{MuA}$, the in vitro reaction produced a ladder of bands that migrated between the nicked and supercoiled forms of the plasmid. The gel mobilities of these species match that expected for the intramolecular strand transfer products in which only a single $\mathrm{Mu}$ end has become covalently joined to an intramolecular target site. Although the CA sequence was not essential for tetramer formation, it was required for DNA cleavage. The site was used both when present in its natural position, near the Ll site, and artificially placed adjacent to L3.

DMSO allows formation of the MuA tetramer on many DNAs that do not normally support the reaction; only a single end-type MuA-binding site and divalent cations are essential. Tetramers formed under these conditions are active in donor DNA cleavage and strand transfer. Thus, these data strengthen the previous conclusion that the tetramer of MuA is the enzymatically active form of the protein. Furthermore, the specific, efficient formation of tetramers of MuA, whether the donor DNA contained one or six end-type MuA-binding sites, demonstrates that the tetrameric configuration of $\mathrm{MuA}$ is an intrinsic property of the protein, independent of the spatial organization of the sites to which it is bound.

Metal ions are not required for specific binding of MuA protein to end-type-binding sites

A divalent metal ion, $\mathrm{Mg}^{2+}, \mathrm{Mn}^{2+}$, or $\mathrm{Ca}^{2+}$, is essential for assembly of the active MuA tetramer (Mizuuchi et al. 1992); the presence of an end-type MuA-binding site is also essential (see above). In an effort to understand how metal ions function in assembly, their effect on specific DNA binding by MuA to the end-type sites was quantitated. The assay used binding of MuA to a ${ }^{32} \mathrm{P}$-labeled synthetic double-stranded oligonucleotide containing two MuA-binding sites and UV-activatible cross-linking groups (azido phenacyl groups; see Materials and methods). After an incubation period to allow MuA binding to the DNA, protein-DNA complexes were covalently trapped by irradiation with UV light. The samples were then run on an SDS-polyacrylamide gel, and the fraction of the ${ }^{32} \mathrm{P}$ label migrating as a covalent complex with the MuA protein was quantitated (see Materials and methods).

Protein-DNA cross-linking demonstrated that MuA 
bound to its recognition sequence in the absence of any added divalent metal ions (Fig. 4A). The efficiency of cross-linking at different concentrations of $\mathrm{MuA}$ indicated that the affinity of MuA for the DNA was lower in the presence of $\mathrm{Mg}^{2+}$ or $\mathrm{Ca}^{2+}$ than in their absence. Cross-linking in the absence of metal reflected specific binding of MuA protein to its recognition sequences, as revealed by the effect of specific and nonspecific DNA competitors (Fig. 4B). Thus, the critical role of divalent metal ions in the assembly of the MuA tetramer cannot be attributed to a requirement for specific DNA binding of MuA to the end-type sites.

\section{Multiple MuA-binding sites act together in tetramer assembly}

In the presence of DMSO, a single end-type MuA-binding site and divalent metal ions are the minimal requirements for promoting tetramer formation by $\mathrm{MuA}$. As metal ions are not essential for DNA binding, our hypothesis is that both the end-type binding sites and the metal ions accelerate or stabilize a conformational change in MuA protein that is necessary for it to tetramerize. DMSO may also stabilize this altered conformation and thus render the other reaction components that are normally essential to the assembly process unnecessary. Therefore, we tested whether those features that became unnecessary in DMSO, such as multiple MuA-binding sites with specific spacing and geometry and the IAS and HU protein, exhibit a stimulatory effect on the reaction occurring in DMSO.

The impact of neighboring MuA-binding sites in tet- ramer assembly could be demonstrated in the presence of DMSO under several conditions. For example, digestion of the donor plasmids into fragments revealed the cooperative participation of the three end-type sites present at each Mu DNA end. Although on a supercoiled plasmid, a single MuA-binding site was sufficient to promote assembly, linearization of the plasmids carrying $L 1$ or $\mathrm{R} 1+\mathrm{R} 2$ rendered these DNAs much poorer assembly cofactors (Fig. 5). In contrast, DNAs that contained either the whole L- or R-end, or both ends, functioned well whether linearized or supercoiled (L-end shown in Fig. 5). Digestion of the L-end plasmid with different restriction enzymes revealed that a linear DNA carrying $\mathrm{L} 2+\mathrm{L} 3$ was also a poorer activator of tetramer formation than the intact L-end (data not shown). Thus, on long linear DNAs under these conditions, at least three end-type MuA-binding sites cooperate in the assembly of MuA tetramers. The behavior of the different DNA substrates as effectors of MuA assembly indicates that MuA monomers may be preferentially added to the forming complex by binding to DNA. Perhaps on supercoiled DNA in the presence of DMSO, nonspecific DNA sites can participate as partners in this process. Reducing the size of the fragment carrying the MuA-binding sites partially restored the ability of the $\mathrm{L} 1$ and $\mathrm{R} 1+\mathrm{R} 2 \mathrm{DNAs}$ to support MuA assembly (Fig. 5), indicating that assembly of the MuA tetramer is sensitive to several different properties of the DNA cofactor, including DNA topology and length.

In addition to the cooperation between neighboring MuA-binding sites, sites present on the two ends act together during assembly. When the time course of tet-

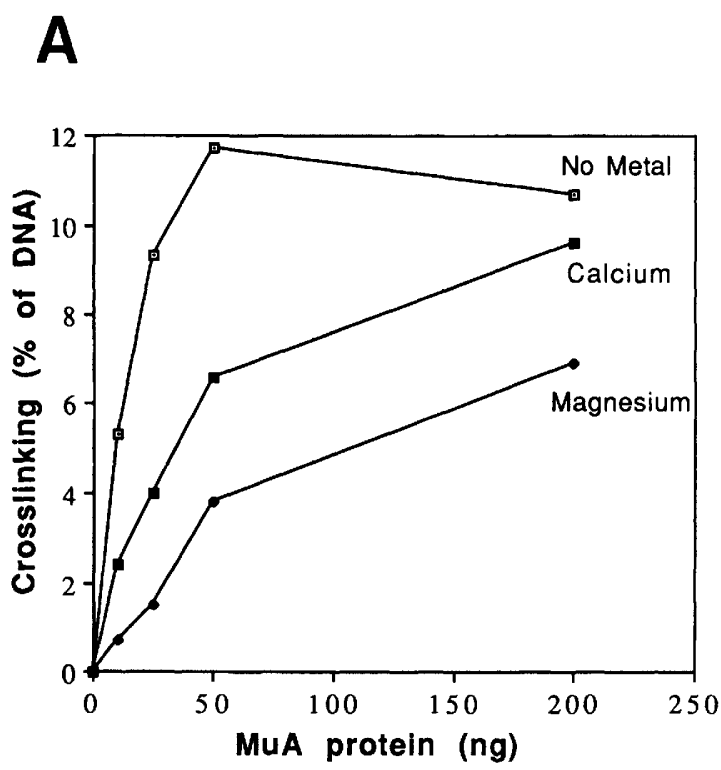

B

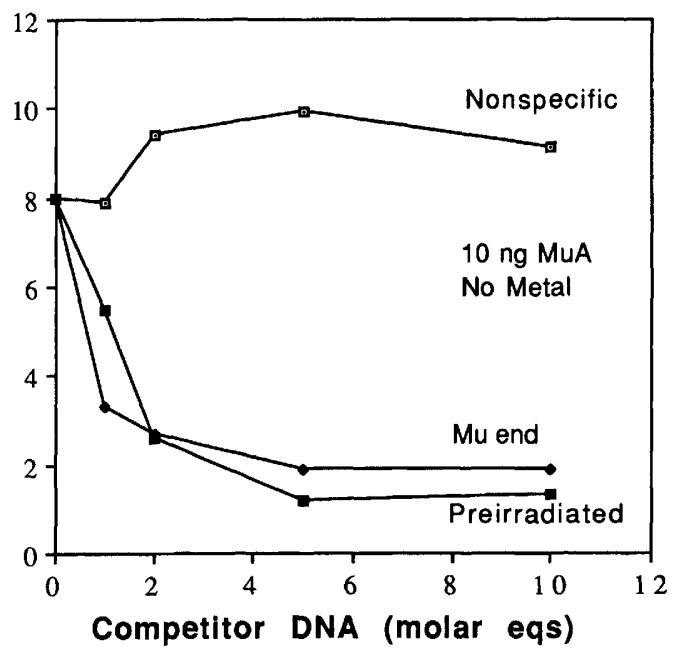

Figure 4. MuA protein binds specifically to end-type sites in the absence of divalent metal ions. (A) A MuA protein titration in the absence of divalent metal ions and in the presence of $10 \mathrm{mM} \mathrm{CaCl}{ }_{2}$ or $\mathrm{MgCl}_{2} ;(B)$ Competition experiment to demonstrate the specificity of MuA binding by this cross-linking assay. The specific competitor was a duplex 52-bp synthetic fragment containing two MuA-binding sites. The nonspecific competitor was a 57-bp synthetic fragment with no Mu sequences. The cross-linking substrate, preirradiated for $3 \mathrm{~min}$ before its addition to the reactions was also used as a competitor. 


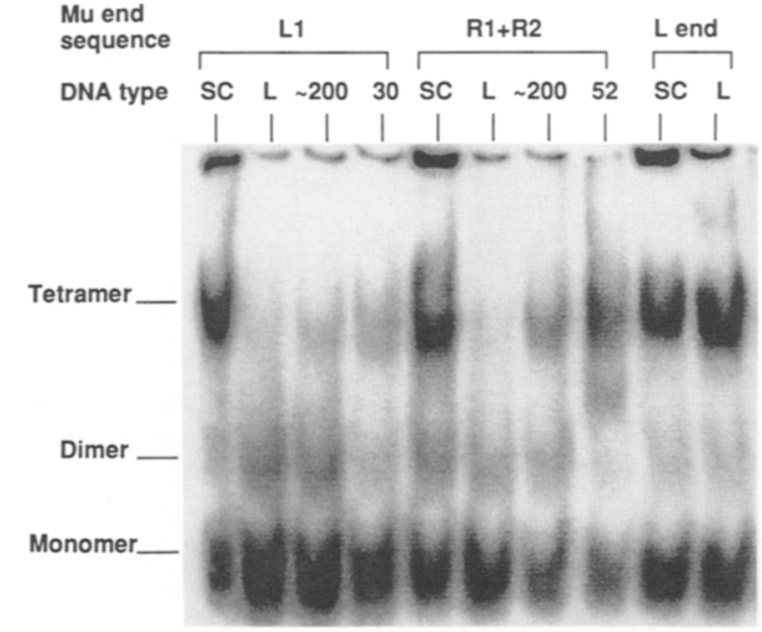

Figure 5. Tetramer formation on linear samples and fragments. The plasmids were L1 (pNK5), R1 + R2 (pKN13), and L-end (+IAS) (pMK590). Each plasmid was linearized with EcoRI for the linear sample (L). pNK5 was cleaved with BamHI and $E c o$ RI, and pKN 13 was cleaved with BamHI and HindIII to make the $\sim 200$-bp fragments. The small fragments were synthetic oligonucleotides (described in Materials and methods).

ramer assembly on various supercoiled plasmids containing different numbers and configurations of MuAbinding sites was measured, their behavior generally fell into two classes (Fig. 6; data not shown). With the first class, which included the wild-type plasmid, tetramer assembly was completed between 5 and $10 \mathrm{~min}$ at $30^{\circ} \mathrm{C}$ (Fig. 6). In contrast, with the second class, the rate of tetramer formation was much slower, having a lag of $\geqslant 2$ min and continuing for $>30 \mathrm{~min}$ (Fig. 6). The critical difference between the DNA substrates in the two classes was whether they contained one or two $\mathrm{Mu}$ ends. The plasmids carrying either the L-end, the R-end, or both ends supported similar rates of tetramer assembly whether or not they also carried the IAS, indicating that it is an interaction between the two ends, rather than interactions with the ends and the IAS, that is responsible for the faster rate of assembly.

The reaction time courses shown in Figure 6 demonstrate this stimulatory effect of having two $\mathrm{Mu}$ ends together on a plasmid on the rate of tetramer assembly. Both the plasmid containing the R-end alone (R-end) and the one carrying the L1 sequence alone (L1) supported the slower rate of complex assembly. When these two sequences were present on the same plasmid (Rend $+\mathrm{L} 1$ ), however, tetramer formation occurred at nearly the same rate as on the wild-type plasmid. A dramatic demonstration of this synergy was seen on the plasmid carrying two R-ends; on this DNA, tetramer formation was complete within $2 \mathrm{~min}$.

The two $\mathrm{Mu}$ ends are normally in inverted orientation with respect to each other, and this configuration is necessary for assembly of the SSC under normal reaction conditions (Mizuuchi et al. 1992). We therefore checked whether the cooperation between the two ends in complex assembly depended on the orientation of the MuAbinding sites. The rate of tetramer assembly was examined on a donor plasmid identical to the wild-type DNA except that the R-end was inverted. Tetramer formation on this plasmid followed the time course similar to that of the single-end-containing plasmids (Fig. 6; wrong ori), indicating that when the two ends were present in the wrong relative orientation they failed to act cooperatively in tetramer assembly.

Previously, our laboratory has demonstrated that the ability of the $\mathrm{Mu}$ transposition reaction to distinguish the orientation of the $\mathrm{Mu}$ end sequences depends on structural information gained from the conformation of negatively supercoiled DNA (Craigie and Mizuuchi 1986). The effect of DNA supercoiling on tetramer formation was therefore analyzed. In the presence of DMSO, supercoiling of the donor DNA was not needed for efficient formation of the MuA tetramer on the wildtype plasmid; the time course of formation of the complex was not greatly altered by relaxation of the DNA (data not shown). In contrast, on the plasmid with the ends in the wrong orientation, relaxation of the DNA reproducibly accelerated the rate of tetramer assembly (data not shown). Thus, under these conditions, negative supercoils appear to inhibit the cooperativity between the improperly oriented ends. This effect of the $\mathrm{Mu}$ end orientation and the DNA superhelicity on the kinetics rather than the extent of tetramer formation by $\mathrm{MuA}$ argues that the structure of an assembly intermediate on the pathway to the SSC is stabilized by the conformation of negatively supercoiled DNA.

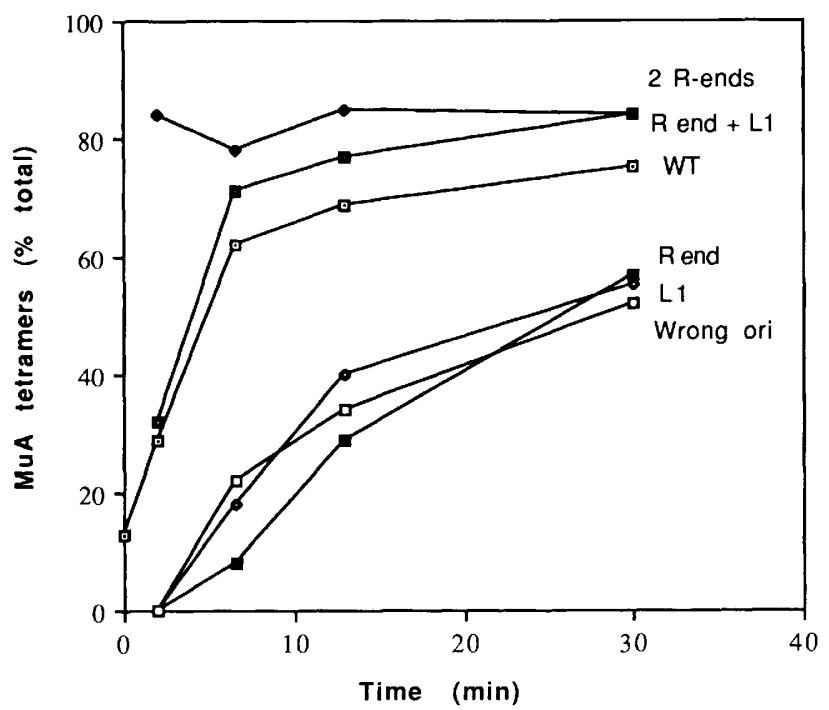

Figure 6. Time course of tetramer formation with different DNAs. All reactions contained $15 \%$ DMSO, and incubation was at $30^{\circ} \mathrm{C}$ for the time indicated before cross-linking. Accumulation of the tetrameric form of MuA was quantitated as described in Materials and methods. The percent of MuA as the tetramer was probably overestimated by the quantitation and thus should be taken only as a measure of the relative assembly efficiency within the experiment. 


\section{Role of the HU protein in assembly}

The HU protein is required for tetramer assembly under normal reaction conditions (Mizuuchi et al. 1992), and, in the presence of DMSO, it stimulates the reaction. Where and how HU functions in construction of the complex was suggested by its effect on tetramer formation promoted by the different mini-Mu plasmids in the presence of DMSO (Fig. 7). Tetramer assembly on plasmids carrying both ends was stimulated by $\mathrm{HU}$, whereas assembly on those carrying only R-end sequences (either the entire R-end or just $\mathrm{R} 1+\mathrm{R} 2$ ) was insensitive to $\mathrm{HU}$; the plasmid containing two R-ends was also not influenced by $\mathrm{HU}$ (data not shown). In contrast, tetramer formation on the L-end was strongly stimulated by HU /Fig. 7). The role of HU was not correlated with IAS function, as assembly on both the $\triangle$ IAS plasmid and the plasmid carrying only the Ll site was clearly stimulated. This result suggests that under normal conditions, $\mathrm{HU}$ helps $\mathrm{MuA}$ bound at the Ll site to participate in assembly, perhaps by binding and bending the DNA segment near L1. The HU protein also stimulated tetramer formation on all of the plasmids shown in Figure 3, including the L1 sequence divorced from the adjacent cleavage site and the L3 sequence (data not shown). Thus, neither the cleavage site nor something unique to the $\mathrm{Ll}$ sequence is essential for the stimulation of assembly by the HU protein. The Ll site is unique in that it is separated by $70 \mathrm{bp}$ from L2. In contrast, R1 and R2 are juxtaposed. Perhaps the L-end configuration necessitates the participation of $\mathrm{HU}$.

\section{Role of the IAS in assembly}

Although both the end-type sites and the IAS bind MuA and participate in the assembly of the MuA tetramer, the data summarized above establishes that their functions are distinct. End-type sites alone can activate $\mathrm{MuA}$ assembly, whereas the IAS cannot; multiple end-type sites cooperate in assembly but this type of cooperativity between end-type sites and the IAS has not been detected. The IAS is not very important in the presence of DMSO; all of the plasmids that support tetramer formation do so equally well in the absence or presence of this "enhancer" sequence. Some hints about the role of the IAS are evident, however, in the results of the following experiment.

As shown above, the plasmid carrying two R-ends efficiently promoted tetramerization of $\mathrm{MuA}_{\text {; }}$ the time required for assembly was shorter than that needed for the wild-type plasmid (see Fig. 6). Furthermore, neither HU nor the IAS was required (see above). This two-R-end plasmid promoted tetramer formation even in the absence of DMSO under certain conditions (Fig. 8). Under these conditions (see legend to Fig. 8), the wild-type plasmid and $\Delta \mathrm{R} 3$ were also active, although plasmids that carried a complete L-and R-end, but lacked the IAS, did not support tetramer assembly. Thus, as with the requirement for HU protein, the dependence of assembly on the IAS is associated with the L-end. In contrast to $\mathrm{HU}$, however, the presence of the IAS on the plasmid containing the L-end alone did not stimulate assembly of the MuA tetramer (see Fig. 3; data not shown). Therefore, we tentatively conclude that the IAS functions to assist an L-end in pairing with an R-end.

\section{Discussion}

The tetramer is an intrinsic form of $M u A$, active for the chemical steps of transposition

Previous analysis of the structure of the stable intermediates in $\mathrm{Mu}$ transposition revealed that the chemical steps of recombination are promoted by a tetramer of

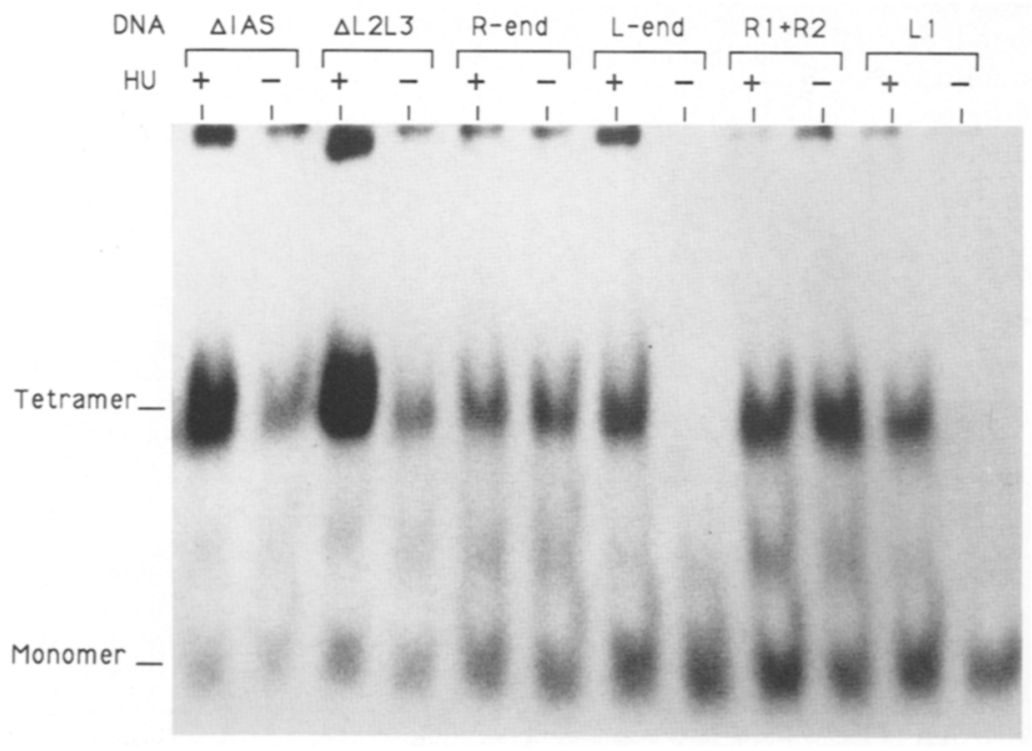

Figure 7. HU helps assembly on the L-end. All reactions were on supercoiled donor plasmids in the presence of $15 \%$ DMSO. Incubation was for 10 $\mathrm{min}$ at $30^{\circ} \mathrm{C}$ before cross-linking. 


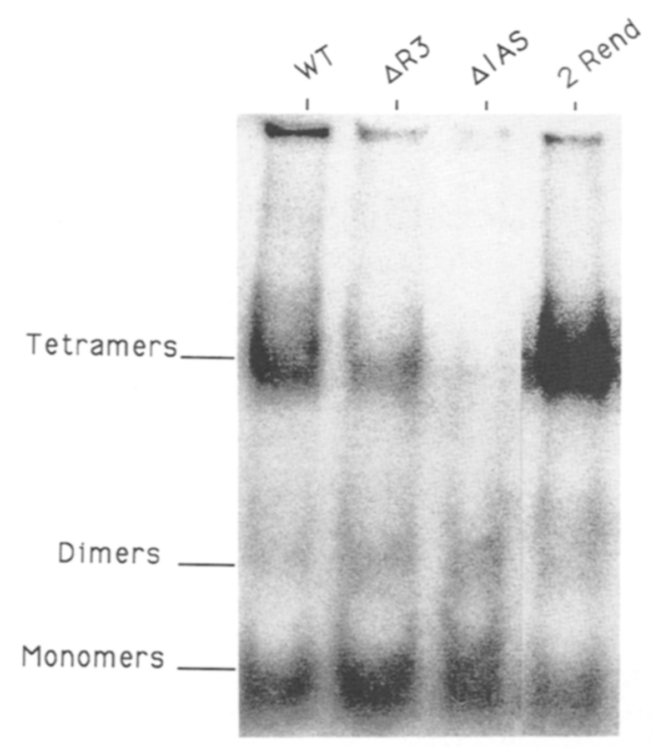

Figure 8. IAS helps pairing the L- and R-ends. Reactions were for $30 \mathrm{~min}$ at $30^{\circ} \mathrm{C}$ in the absence of DMSO. The reaction conditions were $25 \mathrm{mM}$ HEPES at $\mathrm{pH} 7.3,10 \mathrm{mM} \mathrm{MgCl}_{2}, 15 \%$ glycerol, and $\sim 120 \mathrm{~mm} \mathrm{NaCl}$. Under these conditions, the two-Rend plasmid is very active. This is in contrast to our standard reaction conditions $\left[25 \mathrm{~mm}\right.$ Tris- $\mathrm{HCl}(\mathrm{pH} 8.0), 10 \mathrm{mM} \mathrm{MgCl}_{2}$, $156 \mathrm{~mm} \mathrm{NaCl}$, and 0,5 , or $15 \%$ glycerol], in which the wild-type plasmid containing an L- and an R-end and the IAS, is more active than the two-R-end plasmid.

MuA protein bound to the ends of the Mu DNA (Lavoie et al. 1991; Mizuuchi et al. 1992). Under special reaction conditions, the requirements for the assembly of this complex are remarkably relaxed; any plasmid carrying at least one end-type MuA-binding site will support tetramer formation. Tetramer formation is efficient, and tetramers are the most abundant multimeric form of MuA produced whether the DNA carries one or six endtype MuA-binding sites. It was possible that within the SSC and CDC, the ability of MuA to be cross-linked as a tetramer was mainly a result of its being bound to closely spaced sites on the donor DNA. Specific formation of MuA tetramers on DNAs with very different numbers and geometries of MuA-binding sites, however, demonstrates that the tetrameric configuration is an intrinsic property of the protein, independent of the structure of the DNA to which it is bound. Under the relaxed conditions for tetramer assembly, donor cleavage and strand transfer also occur with DNA that is normally inert for transposition; a single MuA-binding site and a CA dinucleotide 4 bp away are all that is required. These data indicate that tetramers of $\mathrm{MuA}$ are active in promoting recombination, regardless of the pathway by which they are formed.

\section{DMSO relaxes the reaction requirements}

In the presence of DMSO, a single end-type Mu-A binding site on a plasmid is sufficient to promote tetramer assembly. Although we do not yet know the basis of the effect of DMSO, adding glycerol and lowering the ionic strength in the reaction have a similar, but less dramatic effect. These solvent conditions might ease the conformational change in MuA, or the MuA-DNA complex, such that the reaction requirements are relaxed. It is important to note that although DMSO relaxes the reaction requirements, it does not seem to provide an entirely new pathway for MuA tetramer assembly; essentially all of the reaction components critical in the absence of DMSO still exhibit stimulatory effects in the presence of DMSO under appropriate reaction conditions. Use of these relaxed conditions thus allowed the roles of several of the factors involved in formation of the SSC to start to be addressed. Our current ideas about the function of the different reaction components in assembly are summarized in Table 1 and discussed briefly below.

\section{Roles of the multiple reaction components in tetramer assembly}

The 22-bp end-type MuA-binding sites are essential to the assembly of the MuA tetramer, as is a divalent metal ion and several minutes of incubation at a relatively high temperature. Binding to its specific DNA site under these reaction conditions apparently potentiates multimerization of MuA. Tetramer assembly probably involves a conformational change in the protein promoted by DNA binding and metal ions; this step may be reflected in the high activation energy for the assembly indicated by its requirement for incubation above $20^{\circ} \mathrm{C}$. The role of metal ions in assembly is not known; how-

Table 1. Function of different reaction components in assembly

\begin{tabular}{|c|c|}
\hline Reaction component & Proposed function \\
\hline End-type & promote a conformational change in \\
\hline $\mathrm{Mg}^{2+}$ or $\mathrm{Mn}^{2+}$ & $\begin{array}{l}\text { required for the enzymatic activities } \\
\text { of MuA; allows assembly of the } \\
\text { "active pocket" of the protein } \\
\text { during tetramer formation }\end{array}$ \\
\hline $\mathrm{HU}$ & $\begin{array}{l}\text { acts near L1 to allow it to participate } \\
\text { in assembly }\end{array}$ \\
\hline IAS & $\begin{array}{l}\text { helps complex formation specifically } \\
\text { between the L- and R-end }\end{array}$ \\
\hline Supercoiling & $\begin{array}{l}\text { brings properly oriented L- and R-ends } \\
\text { together to allow them to } \\
\text { cooperatively participate in } \\
\text { assembly; needed to achieve the } \\
\text { optimal conformation of the IAS in } \\
\text { the absence of IHF }\end{array}$ \\
\hline IHF & $\begin{array}{l}\text { binds to its specific site in the IAS to } \\
\text { achieve the optimal geometrical } \\
\text { conformation of this DNA } \\
\text { segment }^{a}\end{array}$ \\
\hline
\end{tabular}

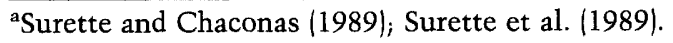


ever, their requirement for specific binding of $\mathrm{MuA}$ to the end-type sites has been eliminated. $\mathrm{Mg}^{2+}$ or $\mathrm{Mn}^{2+}$ is essential for DNA cleavage and strand transfer. Therefore, in addition to their role in tetramer assembly, these metal ions probably participate in cleavage of the DNA phosphodiester bond, as has been described for several nucleases that, as with MuA, depend on these ions for activity (Beese and Steitz 1991; Suck 1992). Because assembly of the tetramer activates the protein for the chemical steps, the active site or sites on the protein may be assembled or uncovered by tetramerization. Perhaps the proper conformation of the active site region is only achieved, or is significantly stabilized, when metal ions and DNA are bound by the protein.

Apparently once a monomer of $\mathrm{MuA}$ is bound to its DNA site, it can attract other monomers, perhaps bound to nonspecific DNA sites. A similar type of complex assembly between individual monomers bound to isolated single sites is seen for the FLP site-specific recombinase of the yeast $2 \mu$ plasmid. On DNA sites that carry only half of the normal binding site dyad, binding of one FLP monomer recruits another to make dimer and some trimer and tetramer complexes (Qian et al. 1990; Amin et al. 1991). Formation of the dimer by protein-protein contacts, brings two DNA sites together and forms a complex active in recombination. Recent studies of FLP multimers assembled on "half-site" substrates indicate that the active site of the protein is actually assembled by dimerization of the protein (Chen et al. 1992). Assembly of the active site of the protein during multimerization is clearly also a possibility with MuA.

If one function of the MuA-binding sites is to promote a conformational change in MuA that is required for multimerization, it is easy to envision that on a DNA substrate carrying multiple binding sites, depending on kinetic parameters and component concentrations, the probability of achieving the proper final oligomeric conformation of the protein within a given time could be increased. Accelerated formation of the same protein configuration is the effect seen by comparing tetramer assembly on plasmids carrying a single $\mathrm{Mu}$ end, an Land an R-end, and two R-ends, which require $\sim 30 \mathrm{~min}$, $\sim 7 \mathrm{~min}$, and $<2 \mathrm{~min}$, respectively, to convert $50 \%$ of the $\mathrm{MuA}$ into the tetramer. This phenomenon may be a general explanation for why more protein-binding sites promote a more efficient reaction in many instances. For example, 20 factor-binding sites may be a better "enhancer" than 10 sites, not because 20 molecules of the factor participate in the reaction but because the multiple sites are more efficient at promoting assembly of the factor into an active form. This type of model may also explain why DNA-binding sites, apparently redundant in function, still participate in reactions and are maintained during evolution. The binding sites at the $\mathrm{Mu}$ ends and the IAS both contain redundancies; only two of the three MuA-binding sites, L2, L3, and R3, are necessary to support efficient transposition in vitro in the presence of the other sites, even under stringent reaction conditions (Lavoie et al. 1991), and part of the IAS can be deleted (Surette et al. 1989). This presence of redundant binding sites also indicates that there are most likely redundant pathways for assembly of the protein complex.

The end sequences of some transposable elements other than $\mathrm{Mu}$ carry multiple protein-binding sites that may also promote assembly of the transposition proteins. The ends of $\operatorname{Tn} 7$ are especially reminiscent of the $\mathrm{Mu}$ ends; the left end carries three repeats of an $\sim 30$-bp binding site for the TnsB protein, whereas the right end carries four sites, not all of which are essential for efficient transposition (Arciszewska et al. 1989; Arciszewska and Craig 1991). The maize element En/Spm has an especially complex array of protein-binding sites at its two ends (for review, see Gierl et al. 1989). Multiple, and sometimes redundant, copies of a protein-binding site are a common feature of replication origins and transcription control elements as well. Many of these loci are known to be sites of assembly of higher order proteinDNA complexes (for review, see Echols 1990).

Although more binding sites are increasingly efficient in promoting formation of the MuA tetramer, the organization of these binding sites also appears to be important. Both the L- and R-ends carry three end-type MuAbinding sites, yet the activity of these two DNA segments in tetramer assembly is clearly distinct. In contrast to reactions using the L-end, assembly involving the R-end does not require $\mathrm{HU}$ protein and the pairing of two R-ends occurs efficiently without participation of the IAS under some conditions. The mechanistic basis of this functional asymmetry is not known. The relative binding affinities, the sequence, and the spacing of the end-type sites, however, is different on the two ends. The $\mathrm{L} 1$ site is unique in that it is separated by $70 \mathrm{bp}$ from the nearest site and requires the HU protein to function in assembly. The site recognized by the $\mathrm{Mu}$ DNA packaging protein during phage maturation is juxtaposed to L1 (Groenen and van de Putte 1985), perhaps preventing a MuA-binding site from occupying this position. The R1 and R2 sites are also special in that they are the only pair of sites that form a direct repeat without any intervening nucleotides. Both of these sites are stably bound by the MuA tetramer in the SSC (Mizuuchi et al. 1992). Perhaps this close spacing makes R1 + R2 a superior promoter of complex assembly.

In addition to the end-type MuA-binding sites, assembly of the stable synaptic complex involves those that make up the IAS. Although both types of sites function during SSC formation, the data presented here demonstrate that their roles are distinct. End-type sites activate MuA for multimerization, and several different combinations of these sites cooperatively accelerate the process. In contrast, the IAS alone does not activate assembly, even in the presence of DMSO, and addition of the IAS to either the R- or the L-end plasmid does not accelerate complex formation. Although we cannot yet place the role of the IAS in assembly with confidence, it is required for formation of the MuA complex on DNA carrying an L- and a R-end, under conditions when two $\mathrm{R}$-ends work very efficiently without the IAS. We have no evidence that the IAS can aid complex assembly by 
the two R-end plasmid. This effect may be responsible for the observation that in the presence of the IAS under stringent reaction conditions, the L-end is better at pairing with an R-end than is a second R-end. By this mechanism, the IAS could help to ensure that two of the same types of ends will not efficiently pair.

Although superhelicity of the donor DNA probably influences multiple reaction steps, current evidence indicates that it plays two especially important roles during assembly of the SSC. The rate of tetramer assembly demonstrates the cooperative participation of the two $\mathrm{Mu}$ DNA ends in construction of the MuA tetramer. The end-end interaction appears to be stabilized by negative supercoiling if the two end segments are in their natural orientation. This impact of DNA topology is further reflected in the inhibitory effect of DNA superhelicity on tetramer assembly with plasmids carrying the two ends in the wrong relative orientation. The importance of the geometry of negatively supercoiled DNA in allowing the $\mathrm{Mu}$ transposition reaction to distinguish the relative orientation of even distantly located recombination sites has been demonstrated previously (Craigie and Mizuuchi 1986); the reaction step where this selectivity is achieved is suggested by the experiments presented here. The second important role of DNA superhelicity is in achieving the active conformation of the IAS (Surette and Chaconas 1989; Surette et al. 1989). This role can be fulfilled by the binding of the sequence-specific DNAbending protein IHF to its recognition sequence in the middle of the IAS. Thus, in the presence of IHF, the donor DNA needs to be less negatively supercoiled than in its absence. As the influence of superhelicity and end orientation of tetramer formation can be demonstrated under conditions when the IAS is probably inactive, as well as in the presence of IHF (data not shown), these two roles of DNA superhelicity in assembly of the SSC appear distinct.

A picture of the events involved in assembly of the active tetramer of $\mathrm{MuA}$ is emerging. The process appears to be fixed to maximize formation of the tetramer between the L-and the R-ends of the Mu DNA when they are in the proper, inverted orientation and when the IAS is available, while minimizing formation of this complex when any of these conditions are not met. The impact of DMSO on the transposition reaction reveals the importance of the multiple requirements for assembly of the SSC in controlling the reaction. Under these relaxed conditions, MuA attempts recombination without the IAS; as the IAS is the site of binding of the $\mathrm{Mu}$ repressor (Mizuuchi and Mizuuchi 1989), control of the transposition reaction by the repressor is lost. Perhaps more serious, the specificity for the properly oriented $\mathrm{Mu}$ ends (Craigie and Mizuuchi 1986), and even the requirement for a pair of $\mathrm{Mu}$ ends (this paper), is lost when tetramer assembly is eased. This result reveals that the coordination of the chemical steps that normally exists between the two ends of the Mu DNA is, to a large extent, a result of the controlled pathway for tetramer assembly rather than obligate to the chemical steps themselves. $\mathrm{Mu}$ apparently avoids potentially deleterious recombination events by tightly controlling assembly of the active tetramer of MuA.

\section{Materials and methods}

Reagents and proteins

Buffers, DNAs, and proteins were all as described previously (Baker et al. 1991; Mizuuchi et al. 1991). Additional sources were DSP (Pierce); azido phenacyl bromide (Fluka); ${ }^{125}$ I protein A (NEN); Sequenase (U.S. Biochemical); \$X174 RFI (BRL); and restriction endonucleases (New England Biolabs).

\section{DNA}

For all experiments the "wild-type" mini-Mu donor DNA was pMK586 (Mizuuchi et al. 1991). The derivatives containing fewer MuA-binding sites were of two classes, those made by deleting sites from pMK586 and those made by inserting MuAbinding sites into the pUC19 cloning vector. The pMK586 modifications were made as follows. (1) $\triangle I A S$ : The IAS was removed from pMK586 by removing the BamHI-ClaI fragment and replacing it with a synthetic linker to make pMK588. (2) Wrong orientation: The relative orientation of the two $\mathrm{Mu}$ ends on pMK586 was switched by inverting the EcoRI fragment that carries the entire R-end to make pMK589. (3) L-end (+IAS) was made by deleting the $E c o R I$ fragment containing the R-end from pMK586 to make pMK590. (4) L-end ( $\triangle I A S$ ) was made by deleting this EcoRI fragment from pMK588 to make pMK588 $\Delta$ R. (5) R-end (+IAS) was made by deleting the ClaI-EcoNI fragment from pMK586 and replacing it with a synthetic linker (17 bp) with complementary ends to make pMK586 LL. (6) IAS only was made by deleting the EcoRI fragment carrying the R-end from

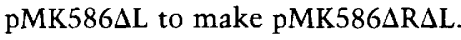

The pUC19 derivatives carrying specific MuA-binding sites were as follows: (1) pKN2 carries R1, R2, and R3; (2) pKN13 carries R1 and R2; (3) pNK10 carries L1, L2, and L3; and (4) pNK 5 carries only L1. These plasmids were generous gifts from Kenji Adzuma and have been described previously (Adzuma and Mizuuchi 1988). Three additional plasmids carrying L1 with the cleavage site removed, L3, and L3 with the cleavage site added were made by inserting the following synthetic oligonucleotides between the BamHI and EcoRI sites of pUC19. The MuAbinding sites are underlined. The sequence added upstream of $\mathrm{L} 3$ is that naturally occurring next to $\mathrm{L} 1$; the $\mathrm{A}$ of the cleavage site is shown in boldface type.

$$
\begin{aligned}
& \text { L1-CA: GATCCTGATTCACTTGAAGTACGAAAAAG } \\
& \text { GACTAAGTGAACTTCATGCTTTTTCTTAA } \\
& \text { L3: GATCCTGTTTCCTTGAAAATACGAAAAAG } \\
& \text { GACAAAGGA } \frac{1}{\text { TCT }} \frac{1}{T} \text { TGCTTTT TTTAA } \\
& \mathrm{L} 3 \text { + CA: GATCCTGTATTGTTTCCTTGAAAATACGAAAAAG } \\
& \text { GACATAACAAAGGAACTTTTATGCTTTTTCTTAA }
\end{aligned}
$$

The Ll-CA oligonucleotide shown here was also that used as a cofactor for MuA assembly in Figure 5. The following oligonucleotide carrying two MuA-binding sites was used as the specific competitor DNA in Figure 3 and the R1 + R2 oligonucleotide for promoting tetramer assembly in Figure 5.

$5^{\prime}$-TATTGATTCACTTGAAGTACGAAAATGTTTCATTAAAAACACGAAAACCGGG
3'-ATAACTAAGTGAACTTCATGCTTTTACAAAGTAATTTTTGTGCTTTTGGCCC

Other donor plasmids were $\Delta \mathrm{R} 3$ (pKN38), which was made by combining the $\mathrm{R} 1+\mathrm{R} 2$ fragment from $\mathrm{pKN} 13$ with the remaining mini-Mu sequences from $\mathrm{pKN} 19$ and has been described previously (Adzuma and Mizuuchi 1989); two R-ends (pKN37), which is identical to pMK426 (Craigie and Mizuuchi 
1987) except the flanking host DNA between the two R-ends has been replaced with the 526-bp HindIII fragment from SV40 (base pairs 3476-4002). $\Delta \mathrm{L} 2 \mathrm{~L} 3$ (pMK587) was made from the following components: a 39-bp BamHI-HindIII fragment carrying L1, the 526-bp HindIII fragment from SV40, an 87-bp synthetic R-end, and the plasmid DNA vector portion from pKN19. Synthetic DNA substrates used for protein-DNA cross-linking are described below.

\section{Protein cross-linking}

$\mathrm{Mu}$ transposition reactions were assembled similarly to those used for activity assays except for slight modifications to minimize the presence of free primary amines and disulfide-reducing agents. The reaction mixtures $(25$ or $50 \mu l)$ contained pMK586 $(70 \mu \mathrm{g} / \mathrm{ml}), \mathrm{MuA}(39 \mu \mathrm{g} / \mathrm{ml}), \mathrm{HU}(12 \mu \mathrm{g} / \mathrm{ml}), 156 \mathrm{mM}$ $\mathrm{NaCl}, 25 \mathrm{~mm}$ HEPES-NaOH (pH 7.8), 15\% (vol/vol) glycerol, and $10 \mathrm{mM} \mathrm{MgCl}_{2}$. Reactions also contained 15\% DMSO when indicated. The assembly of the MuA-DNA complex was stopped by the addition of EDTA (pH 8.0$)$ to $20 \mathrm{mM}$. The reactions were adjusted to $0.5 \mathrm{M} \mathrm{NaCl}$ to dislodge $\mathrm{HU}$ and weakly bound MuA and were treated with $200 \mu \mathrm{g} / \mathrm{ml}$ of DSP for $15 \mathrm{~min}$ at room temperature. Cross-linking was stopped by the addition of lysine and Tris- $\mathrm{HCl}(\mathrm{pH} 8.0)$ to 3 and $25 \mathrm{~mm}$, respectively. After stopping the cross-linking reaction, $5 \mu$ l of each sample was mixed with SDS sample buffer lacking any sulfhydryl reagent and loaded on a composite $2 \%$ acrylamide $/ 0.5 \%$ agarose SDS gel as described (Lavoie et al. 1991; Mizuuchi et al. 1992). After electrophoresis, samples were subjected to Western blot analysis with polyclonal antisera to MuA protein and ${ }^{125} \mathrm{I}$-labeled protein $\mathrm{A}$.

For the time-course experiment (Fig. 6), the amount of the MuA present that had been converted to tetramer was quantitated by both Molecular Dynamics PhosphorImager of exposed plates and Scanalytics Master Scan interpretive densitometer analysis of the X-ray film with similar results. Each lane of the gel was scanned, and the percent of the total radioactivity in the lane running at the tetramer position was determined. No attempt was made to adjust for any possible differences in the transfer efficiency or antibody reaction of the tetrameric and monomeric forms of the protein or for the effects of DSP conjugation on these processes. We have found recently that during electrotransfer of the proteins from the composite acrylamideagarose gel, the efficiency of transfer of the tetrameric and monomeric forms of $\mathrm{MuA}$ protein are quite different. As a result, the percent of total MuA judged to be in the tetramer is probably systematically overestimated by this method. Therefore, the percent tetramer formation should be used for comparison of the assembly efficiency within an experiment but should not be taken as an accurate determination of the total amount of MuA in the reaction that was converted into the tetramer.

To address the donor cleavage and strand transfer activity of the complexes analyzed by protein-protein cross-linking, samples of the reactions (usually removed before protein cross-linking) were analyzed by agarose gel electrophoresis as described previously (Baker et al. 1991).

\section{UV cross-linking assay for MuA-DNA binding}

A duplex DNA fragment (74 bp) carrying two MuA-binding sites, analogous to the $\mathrm{R} 1$ and $\mathrm{R} 2$ sequences at the $\mathrm{Mu} \mathrm{R}$-end, was made as follows. A 22-nucleotide DNA oligonucleotide /see sequence below) containing phosphorothioate linkages near its $3^{\prime}$ end was made by automated chemical synthesis on an Ap- plied Biosystems 380B DNA synthesizer using standard $\beta$-cyanoethyl phosphoamidate chemistry. During synthesis, for the first four consecutive cycles, a sulfurizing reagent (Applied Biosystems) was used in place of the standard oxidizing agent. As a result of the substitution, the first four bonds at the $3^{\prime}$ end contained phosphorothioate linkages (underlined in sequence). This DNA was used as a primer for synthesis of the rest of the $\mathrm{Mu}$ end sequence by hybridizing it to a second unmodified oligonucleotide (74 nucleotides) complementary at the $3^{\prime}$ end but with a long $5^{\prime}$ overhang. DNA synthesis with Sequenase (U.S. Biochemicall, [ $\left.{ }^{32} \mathrm{P}\right] \mathrm{dTTP}$, and unlabeled dNTPs completed the double-stranded fragment. In this way, the sulfur groups were positioned in the first MuA-binding site, and the DNA was labeled with ${ }^{32} \mathrm{P}$ at an adjacent nucleotide.

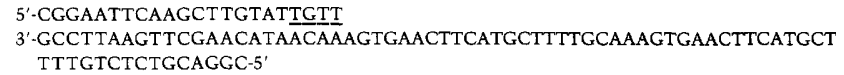

The DNA synthesis reaction by Sequenase was stopped with EDTA and SDS, the reaction was extracted with phenol, passed through a G25 spin column, and the DNA was precipitated with ethanol. The DNA was conjugated with the cross-linking reagent azido phenacyl bromide (AZPB) (Fluka) by resuspending it in $40 \%$ methanol, $20 \mathrm{~mm}$ sodium bicarbonate ( $\mathrm{pH} \sim 9$ ), $0.1 \%$ SDS, and 5 mMAZPB [dissolved initially in dimethylformamide (DMF) $]$ and incubated at room temperature in the dark for $1 \mathrm{hr}$ (Burgin and Pace 1990). The sulfur in the phosphorothioate linkage reacts with the bromide, making a covalent linkage between the DNA backbone and the photoactivatable group. Free crosslinking reagent was removed from the DNA by phenol extraction. Only during and after this conjugation step was the DNA handled in low light.

The MuA DNA-binding reactions contained $25 \mathrm{~mm}$ HEPES (pH 7.6), $290 \mathrm{~mm} \mathrm{NaCl}, 0.1 \%$ Triton X-100, 1\% glycerol, $\sim 100$ ng of the labeled cross-linking substrate, and $10 \mathrm{mM} \mathrm{MgCl}_{2}$ or 10 $\mathrm{mM} \mathrm{CaCl}_{2}$, where indicated. MuA and DNA concentrations are indicated in the legend to Figure 4. Samples were incubated for $10 \mathrm{~min}$ at room temperature before UV. Irradiation was for 3 min at $10 \mathrm{~cm}$, using a shortwave UV light $\left(\sim 190 \mu \mathrm{W} / \mathrm{cm}^{2} ; \lambda \max \right.$ $\sim 250 \mathrm{~nm}$ ). SDS sample buffer was then added, and samples were boiled and run on a $10 \%$ SDS-polyacrylamide gel (NOVEX) in Tris-glycine buffer. ${ }^{32} \mathrm{P}$ Label, shifting to a position in the separating gel (not in the stacking gel) and higher in molecular mass than MuA, was judged to be the cross-linked complex. Under these conditions, the free DNA migrated to the bottom of the gel and the percent of the DNA cross-linked was quantified by measuring the ratio of free and cross-linked DNA by Molecular Dynamics PhosphorImager. After DNase treatment of the samples, the band of the cross-linked complex disappeared, and ${ }^{32} \mathrm{P}$ label comigrated with the MuA protein marker (data not shown).

\section{Acknowledgments}

We thank Michiyo Mizuuchi and Kenji Adzuma for gifts of plasmid DNA and Alan Engelman, Sa dra Gilbert, Michiyo Mizuuchi, and Harri Savilahti for helpfrl comments on the manuscript. T.A.B. is supported by a Helen Hay Whitney Foundation postdoctoral fellowship. This work was supported in part by the National Institutes of Health Intramural AIDS Targeted Antiviral Program.

The publication costs of this article were defrayed in part by payment of page charges. This article must therefore be hereby 
marked "advertisement" in accordance with 18 USC section 1734 solely to indicate this fact.

\section{References}

Adzuma, K. and K. Mizuuchi. 1988. MuA protein-induced bending of the Mu end DNA. In Structure and expression. Vol. 3: DNA bending and curvature. (ed. W.K. Olson, M.H. Sarma, R.H. Sarma, and M. Sundaralingam|, pp. 97-104. Adenine Press, Schenectady, New York.

1989. Interaction of proteins located at a distance along DNA: Mechanisms of target immunity in the Mu DNA strand-transfer reaction. Cell 57: 41-47.

Amin, A., H. Roca, K. Luetke, and P.D. Sadowski. 1991. Synapsis, strand scission, and strand exchange induced by the FLP recombinase: Analysis with half-FRT sites. Mol. Cell. Biol. 11: 4497-4508.

Arciszewska, L.K. and N.L. Craig. 1991. Interaction of the Tn7encoded transposition protein TnsB with the ends of the transposon. Nucleic Acids Res. 19: 5021-5029.

Arciszewska, L.K., D. Drake, and N.L. Craig. 1989. Transposon $\operatorname{Tn} 7$ cis-acting sequences in transposition and transposition immunity. J. Mol. Biol. 207: 35-52.

Baker, T.A., M. Mizuuchi, and K. Mizuuchi. 1991. MuB protein allosterically activates strand transfer by the transposase of phage Mu. Cell 65: 1003-1013.

Beese, L.S. and T.A. Steitz. 1991. Structural basis for the $3^{\prime}-5^{\prime}$ exonuclease activity of Escherichia coli DNA polymerase I: A two metal ion mechanism. EMBO I. 10: 25-33.

Burgin, A.B. and N.R. Pace. 1990. Mapping the active site of ribonuclease $P$ RNA using a substrate containing a photoaffinity agent. $E M B O$ I. 9: 4111-4118.

Chen, J.-W., J. Lee, and M. Jayaram. 1992. DNA cleavage in trans by the active site tyrosine during Flp recombination: Switching protein partners before exchanging strands. Cell 69: 647-658.

Craigie, R. and K. Mizuuchi. 1986. Role of DNA topology in Mu transposition: Mechanism of sensing the relative orientation of two DNA segments. Cell 45: 793-800.

- 1987. Transposition of Mu DNA: Joining of Mu to target DNA can be uncoupled from cleavage at the ends of $\mathrm{Mu}$. Cell 51: 493-501.

Craigie, R., M. Mizuuchi, and K. Mizuuchi. 1984. Site-specific recognition of the bacteriophage $\mathrm{Mu}$ ends by the $\mathrm{Mu}$ A protein. Cell 39: 387-394.

Echols, H. 1990. Nucleoprotein structures initiating DNA replication, transcription, and site-specific recombination. I. Biol. Chem. 265: 14697-14700.

Gierl, A., H. Saedler, and P.A. Peterson. 1989. Maize transposable elements. Annu. Rev. Gent. 23: 71-85.

Groenen, M.A.M. and P. van de Putte. 1985. Mapping of a site for packaging of bacteriophage Mu DNA. Virology 144: 520522 .

Groenen, M.A.M., E. Timmers, and P. van de Putte. 1985. DNA sequences at the ends of the genome of bacteriophage $\mathrm{Mu}$ essential for transposition. Proc. Natl. Acad. Sci. 82: 20872091.

Kuo, C.F., A.H. Zou, M. Jayaram, E. Getzoff, and R. Harshey. 1991. DNA-protein complexes during attachment-site synapsis in Mu DNA transposition. EMBO /. 10: 1585-1591.

Lavoie, B.D., B.S. Chan, R.G. Allison, and G. Chaconas. 1991. Structural aspects of a higher order nucleoprotein complex: Induction of an altered DNA structure at the Mu-host junction of the Mu type 1 transpososome. EMBO I. 10: 30513059 .
Leung, P.C., D.B. Teplow, and R.M. Harshey. 1989. Interaction of distinct domains in $\mathrm{Mu}$ transposase with $\mathrm{Mu}$ DNA ends and an internal transpositional enhancer. Nature 338: 656658.

Maxwell, A., R. Craigie, and K. Mizuuchi. 1987. B protein of bacteriophage $\mathrm{Mu}$ is an ATPase that preferentially stimulates intermolecular DNA strand transfer. Proc. Natl. Acad. Sci. 84: 699-703.

Mizuuchi, K. and K. Adzuma. 1991. Inversion of the phosphate chirality of the target site of $\mathrm{Mu}$ DNA strand transfer: Evidence for a one-step transesterification mechanism. Cell 66: 129-140.

Mizuuchi, M. and K. Mizuuchi. 1989. Efficient Mu transposition requires interaction of transposase with a DNA sequence at the $\mathrm{Mu}$ operator: Implications for regulation. Cell 58: 399-408.

Mizuuchi, M., T.A. Baker, and K. Mizuuchi. 1991. DNase protein analysis of the stable synaptic complexes involved in Mu transposition. Proc. Natl. Acad. Sci. 88: 9031-9035.

- 1992. Assembly of the active form of the transposase$\mathrm{Mu}$ DNA complex: A critical control point in $\mathrm{Mu}$ transposition. Cell 70: 303-311.

Nakayama, C., D.B. Teplow, and R.M. Harshey. 1987. Structural domains in phage $\mathrm{Mu}$ transposase: Identification of the site-specific DNA-binding domain. Proc. Natl. Acad. Sci. 84: 1809-1813.

Qian, X.-H., R.B. Inman, and M.M. Cox. 1990. Protein-based asymmetry and protein-protein interactions in FLP recombinase-mediated site-specific recombination. $J$. Biol. Chem. 265: 21779-21788.

Suck, D. 1992. Nuclease structure and catalytic function. Curr. Opin. Struct. Biol. 2: 84-92.

Surette, M.G. and G. Chaconas. 1989. A protein factor which reduces the negative supercoiling requirement in the $\mathrm{Mu}$ DNA strand transfer reaction is Escherichia coli integration host factor. I. Biol. Chem. 264: 3028-3034.

- 1992. The Mu transpositional enhancer can function in trans: Requirement of the enhancer for synapsis but not strand cleavage. Cell 68: 1101-1108.

Surette, M.G., S.J. Buch, and G. Chaconas. 1987. Transpososomes: Stable protein-DNA complexes involved in the in vitro transposition of bacteriophage Mu DNA. Cell 49: 253262.

Surette, M.G., B.D. Lavoie, and G. Chaconas. 1989. Action at a distance in Mu DNA transposition: An enhancer-like element is the site of action of supercoiling relief activity by integration host factor (IHF). EMBO 1. 8: 3483-3489. 


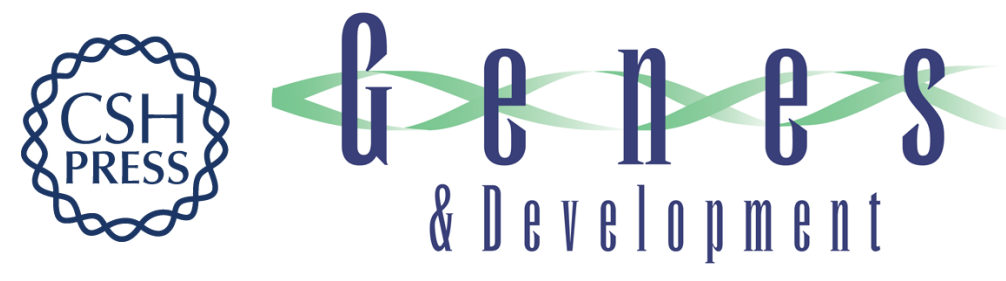

\section{DNA-promoted assembly of the active tetramer of the Mu transposase.}

T A Baker and K Mizuuchi

Genes Dev. 1992, 6:

Access the most recent version at doi:10.1101/gad.6.11.2221

References This article cites 30 articles, 8 of which can be accessed free at: http://genesdev.cshlp.org/content/6/11/2221.full.html\#ref-list-1

License

Email Alerting Receive free email alerts when new articles cite this article - sign up in the box at the top Service right corner of the article or click here.

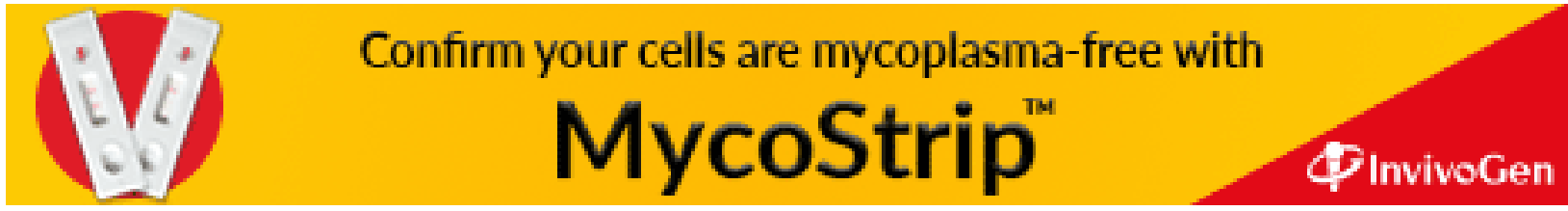

